\title{
Disturbios histológicos causados por Microcyclus ulei y el complejo Colletotrichum spp. en caucho (Hevea brasiliensis)
}

\author{
Olga María Castro-Navarro ${ }^{1}$, Donald Heberth Riascos-Ortiz²®e, Lilliana María Hoyos-Carvajal ${ }^{\circledR}$, \\ Anibal Leonidas Tapiero- Ortiz ${ }^{4}$,
}

${ }^{1}$ I.A. M.Sc. Investigador Máster Corporación Colombiana de Investigación Agropecuaria - AGROSAVIA, Centro de Investigación La Libertad Km 17, Vía Puerto López, CEP 500009, Villavicencio-Meta, Colombia. ${ }^{2}$ I.A. M.Sc. Ph.D. Profesor Ph.D. Fitopatología y Protección de Cultivos, Programa de Agronomía, Universidad del Pacífico, Km 13 vía al Aeropuerto, Barrio el Triunfo Campus Universitario, CEP 764504, Buenaventura, Valle del Cauca, Colombia. ${ }^{3}$ I.A. M.Sc. Ph.D. Profesora Asociada Departamento de Ciencias Agronómica, Facultad de Ciencias Agrarias, Universidad Nacional de Colombia, sede Medellín, Carrera 65 Nro. 59A - 110 Bloque 14, CEP 050034, Medellín, Antioquia, Colombia. ${ }^{4}$ I.A. M.Phil. Ph.D. Investigador Ph.D, AGROSAVIA, Centro de Investigación La Libertad - Km 17, Vía Puerto López, CEP 500009, Villavicencio-Meta, Colombia. Autor para correspondencia: Olga María Castro-Navarro (omcastro@agrosavia.co)

Data de chegada: 10/10/2019. Aceito para publicação em: 15/03/2020.

$10.1590 / 0100-5405 / 229849$

\section{RESUMEN}

Castro-Navarro, O.M.; Riascos-Ortiz, D.H.; Hoyos-Carvajal, L.M; Tapiero-Ortiz, A.L. Disturbios histológicos causados por Microcyclus ulei y el complejo Colletotrichum spp. en caucho (Hevea brasiliensis). Summa Phytopathologica, v.46, n.2, p.105-112, 2020.

Las dos enfermedades más limitantes para el cultivo del caucho en Colombia son el Mal Suramericano de las hojas, ocasionado por Microcyclus ulei y la antracnosis, por Colletotrichum spp. Estos patógenos afectan los tejidos foliares, que bajo condiciones favorables pueden llegar a ocasionar la defoliación total de los árboles. A hojas sanas y enfermas del clon GT1 en distintos estados fenológicos se les realizaron cortes histológicos, los cuales fueron sometidos a tinción doble de safranina-green, previo a la toma de fotografias bajo el microscopio de luz. En las hojas sanas se observó la organización de los tejidos, apreciándose que las hojas adultas presentan una capa fina de ceras, ausente en las hojas jóvenes. Los estados juveniles de las hojas infectadas por M. ulei presentaron degradación y desorganización de la epidermis, parénquima (empalizada y esponjoso) y haces vasculares, mientras que en las hojas adultas se evidenció la formación de estromas acompañada por la desaparición de la epidermis, alargamiento y lignificación de las células del parénquima de empalizada y lignificación parcial. Las hojas en estados juveniles infectadas por Colletotrichum spp. presentaron hundimientos en la epidermis, acompañado por la presencia de lignina; las hojas en estado adulto mostraron depresiones pronunciadas con fuerte lignificación y degradación del parénquima esponjoso o el de empalizada y en ocasiones ambos. En algunas células del mesófilo se observaron hifas y conidias del hongo. En conclusión, se observó que la infección por estos dos patógenos ocasiona daños histológicos de diferente grado, los cuales varían con la edad del tejido y en concordancia con los síntomas visuales.

Palabras clave: histopatología, enfermedades foliares, resistencia ontogénica.

RESUMO

Castro-Navarro, O.M.; Riascos-Ortiz, D.H.; Hoyos-Carvajal, L.M; Tapiero-Ortiz, A.L. Disturbios histológicos causados por Microcyclus ulei e Colletotrichum spp. em seringueiras (Hevea brasiliensis). Summa Phytopathologica, v.46, n.2, p.105-112, 2020.

As duas doenças mais limitantes para o cultivo de borracha na Colômbia são o Mal das folhas causado por Microcyclus ulei e anthracnose, por Colletotrichum spp. Esses patógenos afetam os tecidos foliares, que em condições favoráveis podem resultar no desfolhamento total das árvores. Cortes histológicos de folhas saudáveis e doentes do clone GT1 em diferentes estágios foliares foram realizadas e submetidos a dupla coloração de safranina-green, antes de tirar fotografias ao microscópio de luz. Nas folhas saudáveis foi observada a organização dos tecidos, apreciando que as folhas adultas apresentam uma fina camada de ceras, ausentes nas folhas jovens. Os estágios juvenis das folhas infectadas por M. ulei apresentaram degradação e desorganização da epiderme, parênquima (paliçádico e lacunoso) e feixes vasculares, enquanto nas folhas adultas foi evidenciado a formação de estromas acompanhados pela perda da epiderme, alongamento e lignificação das células do parênquima paliçádico e lignificação parcial. As folhas em estágios juvenis infectadas por Colletotrichum spp. mostraram colapsos na epiderme, acompanhados pela presença de lignina; as folhas do estágio adulto mostraram depressões pronunciadas com forte lignificação e degradação do parênquima lacunoso ou paliçádico e, às vezes, ambas. Em algumas células do mesófilo foram observadas hifas e conídios do fungo. Em conclusão, observouse que a infecção por os dois patógenos provoca danos histológicos de graus variados, que variam com a idade do tecido e de acordo com os sintomas visuais.

Palavras chave: seringueira, histopatologia, doenças foliares, resistência ontogênica.

\section{ABSTRACT}

Castro-Navarro, O.M.; Riascos-Ortiz, D.H.; Tapiero-Ortiz, A.L.; Hoyos-Carvajal, L.M. Histological disturbances caused by Microcyclus ulei and Colletotrichum spp. in rubber trees (Hevea brasiliensis). Summa Phytopathologica, v.46, n.2, p.105-112, 2020.

The two main diseases affecting the rubber tree in Colombia are South American leaf blight caused by Microcyclus ulei and anthracnose caused by Colletotrichum spp. These pathogens affect the leaf tissue and, under favorable climate conditions, can lead to total defoliation of trees. Healthy and symptomatic leaves in different phenological stages of the GT1 clone were histologically sectioned and double stained with safranin-fast green, before pictures were obtained under a light microscope. Tissue organization was observed in healthy leaves, evidencing that mature leaves had a thin wax layer, which was absent in young leaves. Early stages of leaves infected by $M$. ulei showed degradation and disorganization of the epidermis, parenchyma (palisade and spongy) and vascular bundles, while mature leaves had formation of stromata together with epidermis loss, elongation and lignification of the palisade parenchyma cells, besides partial lignification. Young leaves infected by Colletotrichum spp. showed depressions in the epidermis, accompanied by the presence of lignin; mature leaves presented pronounced depressions with strong lignification and degradation of the spongy or palisade parenchyma and sometimes both processes occurred. Fungal hyphae and conidia were observed in some mesophyll cells. In conclusion, infection by both pathogens causes histological damage of varied degrees according to the age of the tissue and the visual symptoms.

Keywords: rubber tree, histopathology, foliar diseases, ontogenic resistance. 
En Colombia, el área sembrada en caucho (Hevea brasiliensis Muell.) es marginal con respecto al potencial productivo del país $(3,25)$. Los cálculos más conservadores estiman en cerca de 263.000 ha el área óptima para el establecimiento de plantaciones de caucho, área que puede ser de hasta 900.000 ha si se incluyen zonas con algún tipo de restricciones para ser consideradas zona de escape a la principal enfermedad denominada Mal Suramericano de las Hojas (4).

En el 2010 había solamente 21.381 ha de caucho sembradas en Colombia. En el 2011 esta cifra aumentó a 25.687 ha (2), en tanto que para el 2017 se tenían poco más de 56.000 ha (11). Con una tasa de incremento anual oscilando alrededor de $30 \%$, en unos pocos años se dispuso de caucho natural para satisfacer la demanda interna (20.295 TM) y se obtuvieron excedentes para exportación. En el ámbito regional, la producción se concentra en Meta (39\%), Santander (22\%), Caquetá (17\%) y Antioquia (10\%)..

Siguiendo lo expuesto por Hallé et al. (18), los ciclos de la ontogenia foliar comprenden cuatro fases relacionadas con el nivel de actividad del meristemo apical y con las fases de desarrollo foliar. La fase A comprende la formación de primordios foliares y de yemas axilares, dura en promedio 9 días; la fase B es la de elongación inicial, tiene una duración media de 10 días y presenta dos etapas: B1, donde los foliolos tienen una concentración alta de antocianina y están en posición vertical con el ápice hacia arriba y B2, donde los ápices de los foliolos se voltean hacia abajo y presentan coloración antociánica menos intensa; en la fase $\mathrm{C}$ los folíolos son flácidos y de color verde, dura aproximadamente 8 días; la fase $\mathrm{D}$ se caracteriza por el desarrollo completo de las hojas y dormancia de la yema apical, dura cerca de 13 días. Durante los estados juveniles del cultivo este proceso se repite por periodos de aproximadamente 12 - 18 días. En clones comerciales, una vez formada la copa del árbol e iniciada la etapa productiva, el proceso ocurre principalmente durante la época seca, 1 o 2 veces al año y dura de 12 - 20 días a partir de la brotación, dependiendo del clon (21). En sentido fisiológico durante el curso de su maduración, las hojas de caucho pasan de ser casi exclusivamente "vertedero" (estados A - C) a "fuente" (estado C). En términos epidemiológicos, con referencia a la expresión de la resistencia genética de la planta a los patógenos el proceso coincide con la migración de estados receptivos a completamente no receptivos a la mayoría de enfermedades foliares, dependiendo de la susceptibilidad (resistencia) del clon.

La enfermedad más limitante para el cultivo del caucho en el Sur y Centroamérica es el Mal Suramericano de las hojas (14), ocasionada por el hongo Microcyclus ulei (Henn.) Arx (Anamorfo: Fusicladium macrosporum Kuijper; syn Pseudocercospora ulei, (Henn.) (5). El patógeno afecta hojas jóvenes en desarrollo, frutos inmaduros y tallos jóvenes de Hevea spp. (1). La incidencia de la enfermedad ocasiona caída prematura de hojas jóvenes y bajo condiciones favorables puede causar la defoliación total; en viveros y jardines clonales ocasiona reducción del crecimiento; en árboles adultos las afecciones sucesivas debilitan las plantas, reduciendo su producción de látex, y en clones muy susceptibles pueden llegar a ocasionar la muerte (13). La enfermedad se presenta prácticamente en todos los países donde se cultiva el caucho.

Desde 1992 se ha venido observando un incremento de la incidencia de antracnosis en Brasil, constituyéndose en un limitante importante para el desarrollo del cultivo en el estado de São Paulo, la región con mayor desarrollo del cultivo (12). En Colombia, la incidencia de la enfermedad ha venido incrementándose, particularmente en áreas de la altillanura próxima a Puerto
Gaitán, Meta, donde se ha desarrollado un núcleo productivo con alrededor de unas 20.000 ha de cultivo. Varias especies dentro de los complejos Colletotrichum gloeosporioides, $C$. boninense y $C$. acutatum han sido identificadas de lesiones de antracnosis en los Llanos Orientales en AGROSAVIA, La Libertad (10).

Además de necrosis y deformación foliar, el principal daño que ocasionan las infecciones por Colletotrichum spp. es la caída secundaria de las hojas, resultado de afecciones durante el proceso de formación del nuevo follaje, luego de la defoliación natural de árboles ya diferenciados (adultos). La destrucción sistemática de las hojas nuevas por re-infecciones durante periodos húmedos debilitan los árboles, producto de disminuciones sustanciales de la densidad foliar; las ramas terminales mueren, ocasionando el síntoma conocido como muerte descendente. Estos daños se reflejan en pérdidas de la producción de látex (17), aunque más importante, modifican la parsimonia de los procesos de defoliación natural anual de los clones comerciales, provocando la exposición de tejidos receptivos a la enfermedad durante las épocas húmedas (10).

Los estudios histopatológicos en enfermedades foliares del caucho son incipientes; éstos permiten apreciar el avance de la enfermedad a nivel del tejido vegetal y observar las estructuras del patógeno involucradas en cada etapa del proceso infectivo. E1 presente estudio aporta información en aspectos histopatológicos relacionados con la incidencia de enfermedades foliares del caucho, a partir de la observación del desarrollo del proceso infectivo de $M$. ulei y Colletotrichum spp. en tejidos de hojas con distintos estados fenológicos del clon GT1; la observación a escala microscópica de las estructuras de los patógenos y la descripción de los disturbios histológicos ocasionados por la infección, en concordancia con los síntomas visuales externos y los daños en los tejidos analizados.

\section{MATERIALES Y MÉTODOS}

\section{Localización}

El estudio se realizó en el Centro Experimental de la Corporación Colombiana de Investigación Agropecuaria (AGROSAVIA) La Libertad, ubicado geográficamente a $9^{\circ} 6^{\prime}$ de latitud norte y $73^{\circ}$ $34^{\prime}$ de longitud oeste, en el km 17 vía Villavicencio Puerto López, a 330 m.s.n.m. La precipitación anual promedio es de $2800 \mathrm{~mm}$, distribuida entre los meses de abril a diciembre, la temperatura promedia de $26^{\circ} \mathrm{C}$ y la humedad relativa media de $85 \%$ en la época lluviosa y $65 \%$ en la seca. El procesamiento y análisis histológico de las muestras se realizó en el Laboratorio de Sanidad Vegetal de la Universidad Nacional de Colombia Sede Bogotá.

\section{Descripción de síntomas y análisis histopatológico}

Se colectaron foliolos sanos y enfermos en los estados fenológicos $\mathrm{B}_{2}$, C y D (18) del clon GT1. La condición de enfermedad fue determinada macroscópicamente mediante sintomatología, a partir de las descripciones reportadas en la literatura para Mal suramericano de las hojas y Antracnosis, causadas por M. ulei y Colletotrichum spp. (15), respectivamente. Los aislamientos de Pseudocercospora ulei, fueron caracterizados por Rodríguez (23) como Microcyclus ulei mediante AFLPs y los de Colletotrichum spp. por Damm et al. $(6,7)$ como C. annellatum y C. lacticphilum.

En el análisis histopatológico se empleó el protocolo propuesto por Prophet et al. (22) para la obtención de cortes histológicos 
en tejido vegetal, modificado. Para tal fin, se realizaron cortes transversales de $5 \mathrm{~mm}$ de diámetro en hojas con y sin síntomas de las enfermedades.

Los cortes fueron procesados de acuerdo con el siguiente procedimiento: (1) Fijación de tejidos por inmersión en FAA (Formaldehido comercial, Alcohol 85\%, Ácido acético glacial), luego se procedió a la (2) Deshidratación de tejidos por inmersión en etanol, consecutivamente y en forma ascendente, a concentraciones de $70 \%, 80 \%, 90 \%, 96 \%$ y $96 \%$. Cada 24 h se hizo el respectivo cambio de alcohol y para la última concentración se dejaron las muestras por dos días consecutivos; seguidamente se realizó el (3) Aclarado de tejidos en alcohol etílico (96\%) grado analítico y terbutanol puro $(100 \%)$, con una relación de $2: 1$ respectivamente. A las 24 horas se realizó el cambio de alcoholes en proporción 1:1; se efectuó un tercer cambio a las 24 horas y se modificó la relación a 1:2, respectivamente; por último se dejaron los tejidos en terbutanol puro. A continuación se llevó a cabo una (4) Imbibición de las muestras en parafina fundida con terbutanol puro en partes iguales a $56^{\circ} \mathrm{C}$ por 3 días, hasta la evaporación del alcohol; seguido por la (5) Deposición de tejidos, para lo cual se dispusieron los cortes en parafina fundida dentro de moldes para obtener bloques; a partir de los cuales se realizaron (6) Cortes transversales de $7 \mu \mathrm{m}$ de espesor, utilizando un micrótomo de rotación tipo Minot. Los cortes fueron dispuestos en láminas portaobjetos, realizando un baño de flotación; posteriormente se colocaron en una estufa a $65{ }^{\circ} \mathrm{C}$ para retirar la parafina. La (7) Tinción de tejidos se llevó a cabo mediante inmersión de los cortes en xilol grado comercial durante $10 \mathrm{~min}$, luego en etanol $96 \%$ durante $5 \mathrm{~min}$, seguido de un lavado en agua corriente.

Las placas con los cortes se colocaron en safranina al $1 \%$ (19) durante $24 \mathrm{~h}$ y seguidamente se procesaron con alcohol $96 \%$ adicionado con $0,5 \mathrm{~g}$ de ácido pícrico por $15 \mathrm{seg}$, alcohol amoniacal al 1\% durante $2 \mathrm{~min}$, etanol al 96\% (5 min), Fast Green por $10 \mathrm{seg}$ (19), esencia de clavos por 2 min; proceso concluido mediante 2 lavados en etanol al 96\%, durante $5 \mathrm{~min}$.

Finalmente las placas se colocaron en isopropanol grado analítico durante $5 \mathrm{~min}$ y en xilol $96 \%$ durante $10 \mathrm{~min}$. El montaje se selló con resina sintética (citoresin), se analizaron los cortes y se tomaron fotografías bajo el microscopio a 100X, 400X y $1.000 \mathrm{X}$, identificando las capas del tejido foliar, su conformación y estado, así como las estructuras de los patógenos estudiados.

\section{RESULTADOS Y DISCUSIÓN}

La observación microscópica de los cortes de las hojas sanas permitió diferenciar la organización de los tejidos (Figura 1a y b; $2 \mathrm{a}$ y b) en conformidad con lo reportado por Gonçalves \& Zieri (16); observándose una capa muy fina de ceras en las hojas adultas, ausente en las hojas jóvenes (Figura 2b). Los foliolos jóvenes infectados por M. ulei presentaron deformación acompañada por abundante esporulación conidial. Tanto macro como microscópicamente se observó degradación y destrucción de la epidermis, parénquima (empalizada y esponjoso) y haces vasculares (Figura 1c y d), con presencia de conidias sigmoides del estado anamorfo P. ulei. (Figuras 1e y f); Sambugaro et al. (24) reportaron resultados similares para otro clon susceptible (PB 314 ), en el cual observaron esporulación conidial en las superficies adaxial y abaxial de la hoja, necrosis foliar y degeneración de los tejidos del mesófilo 10 días después de la inoculación (ddi).

En los foliolos adultos se evidenció la formación de estromas (Figuras 2c y d) acompañada por la desintegración de la epidermis; alargamiento y necrosis de las células del parénquima de empalizada, mientras que en los otros tejidos se apreció lignificación parcial (Figuras 2e y f). Sambugaro et al. (24) también reportaron alteración del parénquima de empalizada al inicio de la formación del tejido estromático (45 ddi) en el clon PB 314.

La infección de Colletotrichum spp. en foliolos jóvenes con lesiones necróticas, con bordes definidos y esporuladas, se manifestó microscópicamente con hundimientos (depresión del tejido), degradación y desprendimiento del mesófilo (Figuras 3c, d); con presencia de masas conidiales en acérvulos que sobresalen a la epidermis (Figura 3e).

Los foliolos en estado maduro con deformación y "perdigoneo" mostraron depresiones pronunciadas con fuerte lignificación y degradación del parénquima esponjoso o el de empalizada y en ocasiones ambos (Figuras $4 \mathrm{~b}$ y c), en algunas células del mesófilo se observaron hifas y conidias del hongo (Figura 4c).

En conformidad con lo expuesto por Lieberei et al. (20), los estadíos A, B y C son hojas completamente demandantes de energía ("sink") y carecen casi por completo de lignina; el incremento en el tamaño de la hoja sigue un curso casi exponencial durante las etapas tempranas del desarrollo foliar, con rápido crecimiento de la pared celular y elongación celular; los procesos de endurecimiento de la pared celular se retardan hasta los estados adultos. Estos eventos fisiológicos están relacionados con la receptividad a la infección por inóculo de M. ulei y Colletotrichum spp.; los tejidos de las hojas en fase A son altamente receptivos y su receptividad se transforma hacia completamente resistentes durante la etapa $\mathrm{D}$; esta receptividad relacionada con la edad del tejido foliar (ontogénica) es específica para cada clon (21).

Los resultados obtenidos en este estudio mostraron correspondencia con lo descrito por Lieberei (21); evidenciándose además que la resistencia ontogénica (receptividad) en caucho reportada para $M$. ulei, opera también para Colletotrichum spp. En hojas jóvenes carentes de cutícula y lignina se observa una deformación generalizada de los tejidos por parte de los patógenos analizados; mientras que en las hojas adultas, con la cutícula y lignina desarrolladas, el daño ocasionado por estos patógenos se encuentra limitado a las células epidermales; se sugiere que estos compuestos contribuyen a la expresión de la resistencia de las hojas de caucho.

La resistencia ontógenica (receptividad) ha sido reportada en otros patosistemas, entre los que se incluye el mildeo polvoso (Uncinula necator) - uva (Vitis vinífera), donde se observó una alta susceptibilidad de las bayas en la primera semana de formación del fruto y un incremento en la expresión de la resistencia cuando alcanza 3 semanas de edad (8); este evento fue asociado al incremento en el grosor de la cutícula con la edad del fruto; al porcentaje de grados brix; y a la formación de compuestos fenólicos con actividad antimicrobial (9). En el caso del caucho esta resistencia ha sido asociada, además de la formación de la cutícula y de los compuestos fenólicos, a la producción de lignina, ácido cianhídrico-HCN y escopoletina (21).

Para describir la morfo-histología de hojas de caucho afectadas por hongos fitoparásitos, Sterling et al. (26) siguieron un método de micropreparados de cortes vegetales con tinciones de lugol, lactofenol-ácido, fucsina, lactofenol-azul, anilina-ácido fucsina, 

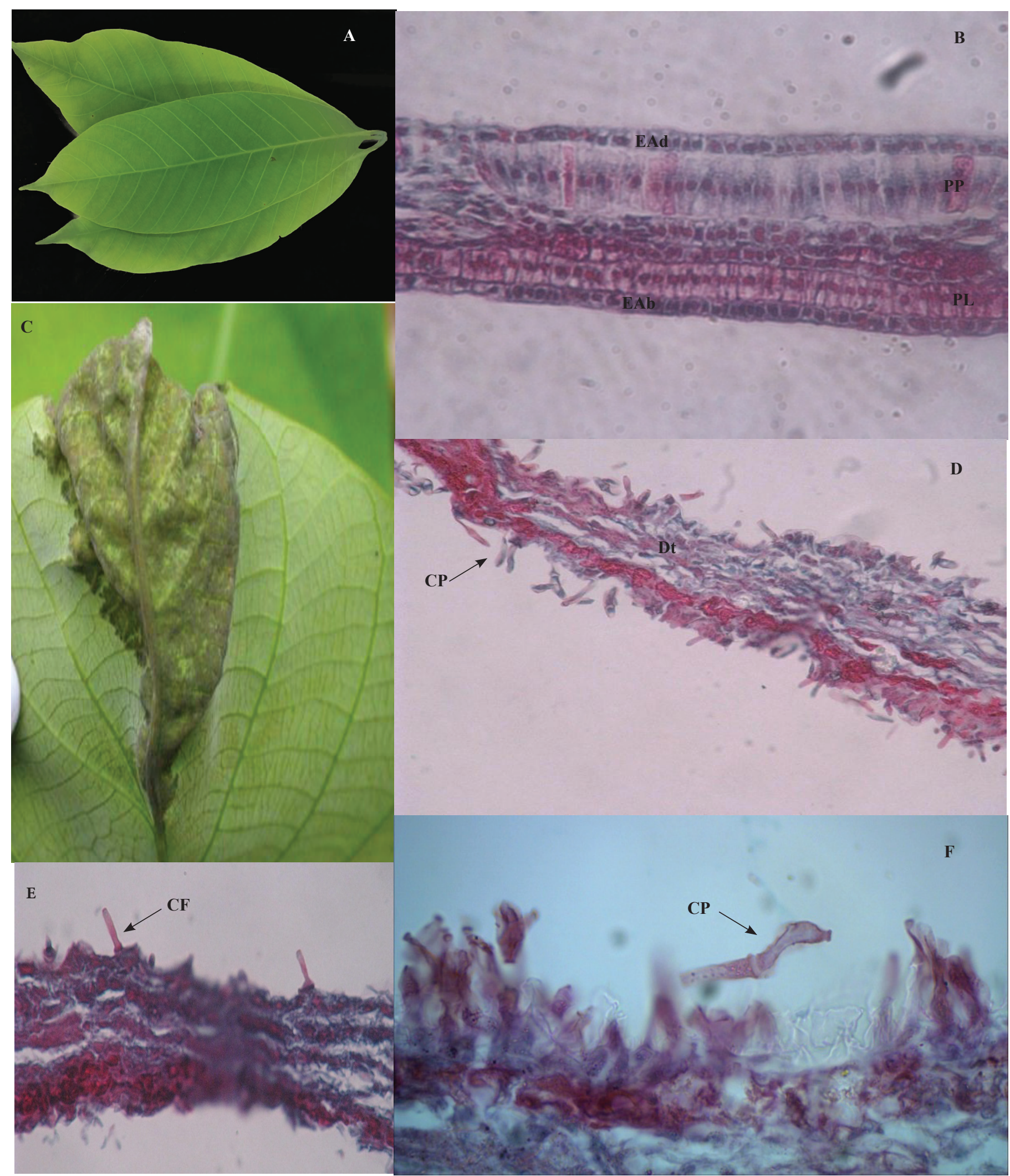

Figura 1. A. Foliolos en estadío C, sanos (18). B. Organización histológica de un foliolo joven sano en estadío C (40x); EAd = Epidermis adaxial; $\mathrm{PP}=$ Parénquima de empalizada; $\mathrm{PL}=$ Parénquima esponjoso; EAb = Epidermis abaxial. C. Síntomas de infección de $M$. ulei en estadío C. D. Daños histológicos por infección de M. ulei en foliolo estadío C (40x); Dt = degradación de los tejidos; CP = conidia de Pseudocercospora ulei (40x) E. CF = Conidióforo de P. ulei en tejido foliar joven (40x). F. CP= Conidia de P. ulei (100x). Fuente: Autores. 


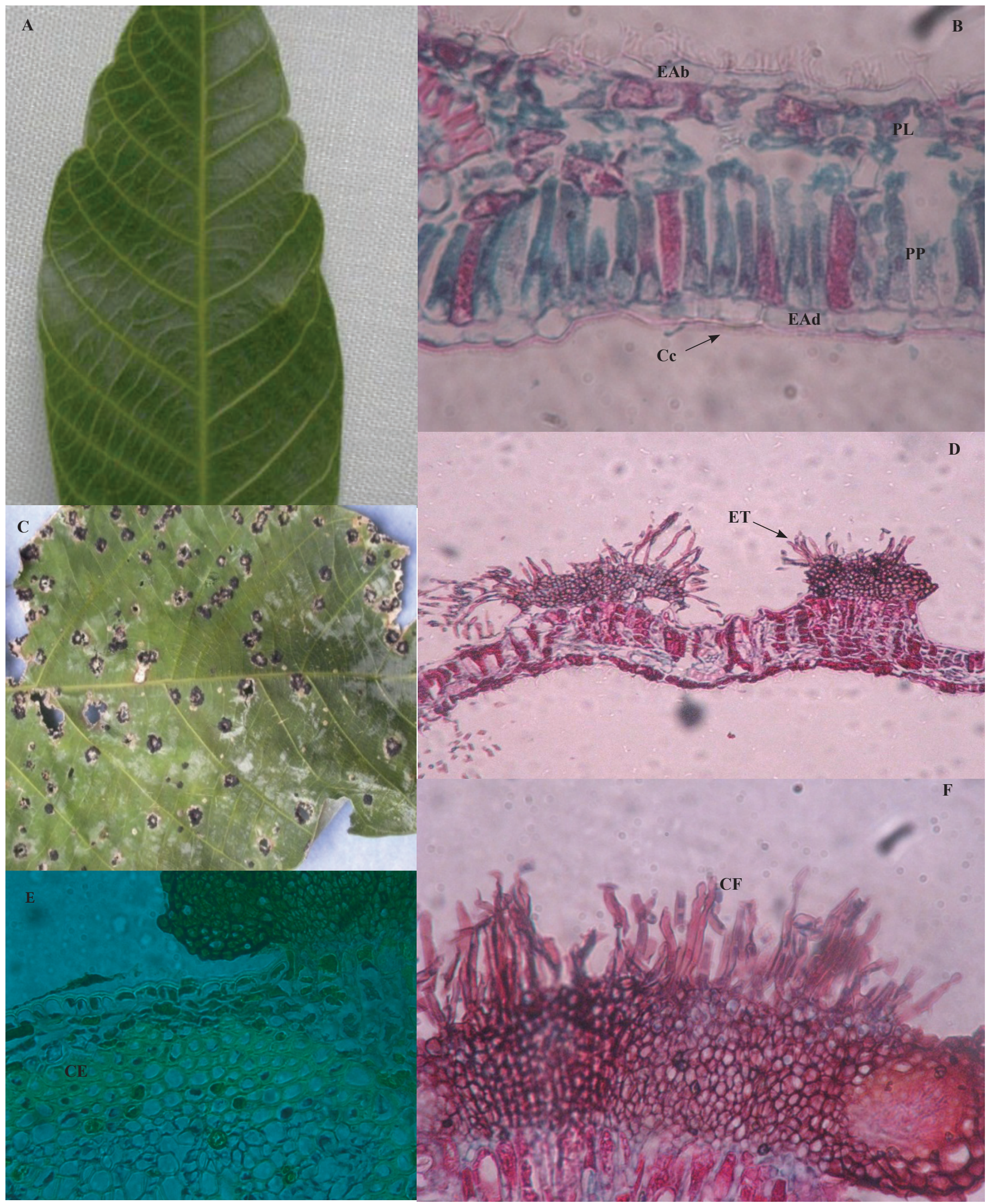

Figura 2. A. Foliolo en estadío D (18). B. Organización histológica de un foliolo maduro y sano en estadío D (40x); Cc = capa cérea; EAd = Epidermis adaxial; $\mathrm{PP}=$ Parénquima de empalizada; $\mathrm{PL}=$ Parénquima esponjoso; $\mathrm{EAb}=$ Epidermis abaxial. C. Foliolo en estadío $\mathrm{D}$ con síntomas de $M$. ulei. D. corte transversal de foliolo en estadío D con estromas de $M$. ulei $=\mathrm{ET}(10 \mathrm{x}) . \mathbf{E} . \mathrm{CE}=$ células esclereidas asociadas a estromas del patógeno (40x). F. CF = conidióforos (40x). Fuente: Autores. 

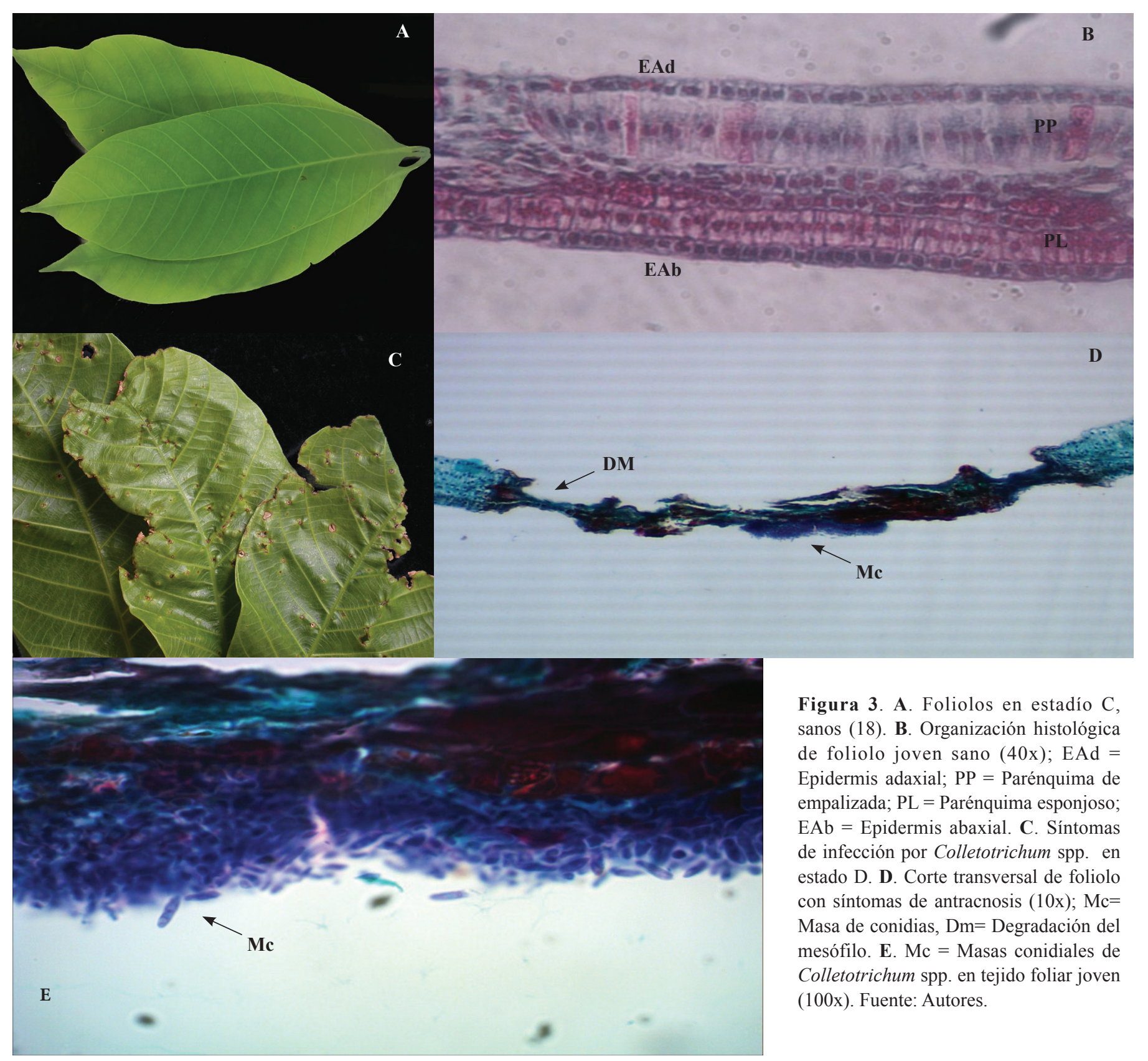

Figura 3. A. Foliolos en estadío C, sanos (18). B. Organización histológica de foliolo joven sano (40x); EAd = Epidermis adaxial; $\mathrm{PP}=$ Parénquima de empalizada; $\mathrm{PL}=$ Parénquima esponjoso; $\mathrm{EAb}=$ Epidermis abaxial. C. Síntomas de infección por Colletotrichum spp. en estado D. D. Corte transversal de foliolo con síntomas de antracnosis $(10 \mathrm{x})$; $\mathrm{Mc}=$ Masa de conidias, $\mathrm{Dm}=$ Degradación del mesófilo. E. $\mathrm{Mc}=$ Masas conidiales de Colletotrichum spp. en tejido foliar joven (100x). Fuente: Autores.

lactofenol-ácido acético y fenol-glicerina; siguiendo esta metodología no se logró una clara definición de los tejidos y de las estructuras del patógeno M. ulei. Por otro lado, Sambugaro et al. (24) estudiaron los aspectos anatómicos de hojas inoculadas con M. ueli en tres clones de caucho, para lo cual emplearon tinción con azul de toluidina, colorante que les permitió observar los sitios en los cuales se acumulan compuestos fenólicos como respuesta a la infección en clones con resistencia moderada.

Los resultados de este estudio demostraron que la técnica histológica y de tinción (safranina-fast green) es útil para distinguir claramente los diversos tejidos foliares del caucho y poder diferenciarlos de las estructuras de los patógenos bajo estudio.

Conflicto de intereses: El manuscrito fue preparado y revisado con la participación de todos los autores, quienes declaramos que no existe ningún conflicto de intereses que ponga en riesgo la validez de los resultados presentados.

\section{AGRADECIMIENTOS}

Los autores agradecen a la Corporación Colombiana de Investigación Agropecuaria (AGROSAVIA) por la financiación de esta investigación, la cual se realizó en el marco del proyecto "Optimización y vinculación de conocimientos y tecnologías para sistemas integrados de producción de la Orinoquia. ACT. Estrategias para el manejo del cultivo del caucho en la altillanura plana CIAT-MADR" y al laboratorio de Sanidad Vegetal de la Facultad de Ciencias Agrarias de la Universidad Nacional de Colombia sede Bogotá por permitir el uso de los equipos y la toma de fotografías por parte de los autores. 

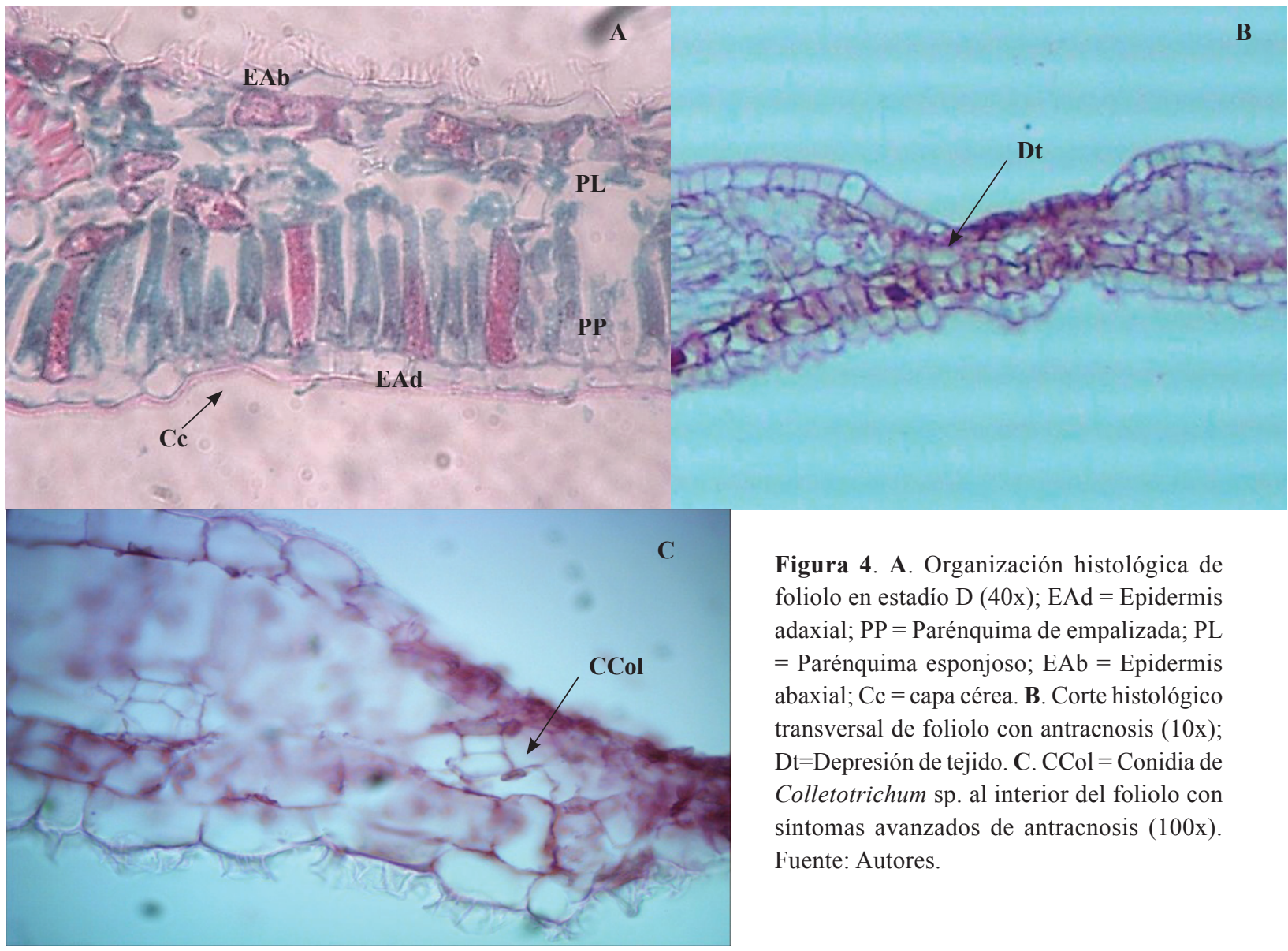

Figura 4. A. Organización histológica de foliolo en estadío D (40x); EAd = Epidermis adaxial; $\mathrm{PP}=$ Parénquima de empalizada; $\mathrm{PL}$ $=$ Parénquima esponjoso; $\mathrm{EAb}=$ Epidermis abaxial; $\mathrm{Cc}=$ capa cérea. $\mathbf{B}$. Corte histológico transversal de foliolo con antracnosis (10x); $\mathrm{Dt}=$ Depresión de tejido. $\mathbf{C}$. $\mathrm{CCol}=$ Conidia de Colletotrichum $\mathrm{sp}$. al interior del foliolo con síntomas avanzados de antracnosis (100x). Fuente: Autores.

\section{BIBLIOGRAFÍA}

1. Chee, K.; Holliday, H. South American Leaf Blight of Hevea Rubber. Kuala Lumpur: Malaysian Rubber Research Development Board, 1986. 50p. (MRRDB Monograph, 13).

2. Confederación Cauchera Colombiana. Informe del Censo Nacional Cauchero 2012. Bogotá: Confederación Cauchera Colombiana, 2012. $15 \mathrm{p}$. Documento Interno.

3. Confederación Cauchera Colombiana. Zonas Caucheras: Censo Cauchero Nacional. El Cauchero, Bogotá, v.1. p.19-20, 2016. Disponible en: $<$ https://docs.wixstatic.com/ugd/e90b5c_b06fc0fea162488cb73f7bb8bc70ad31.pdf>. Acceso en: 15 dic. 2018.

4. CONIF. Avances investigativos en caucho natural. Santafé de Bogotá: CONIF, MADR, 1997. 158p. (Serie Técnica, 37).

5. Da Hora Júnior, B.T.; De Macedo, D.M.; Barreto, R.W.; Evans, H.C.; Mattos, C.R.R.; Maffia, L.A.; Mizubuti, E.S. Erasing the past: a new identity for the Damoclean pathogen causing South American leaf blight of rubber. PLOS ONE, Portland, v.9, n.8, p.1-12, 2014. Disponible en: $<$ https://journals.plos.org/plosone/article?id=10.1371/journal. pone. $0104750>$. Acceso en: 3 mayo 2018.

6. Damm, U.; Cannon, P.F.; Woudenberg, J.H.C.; Johnston, P.R.; Weir, B.S.; Tan, Y.P.; Shivas, R.G.; Crous, P.W. The Colletotrichum boninense species complex. Studies in Mycology, Utrecht, v.73, p.1-36, 2012. Disponible en: https://www.ncbi.nlm.nih.gov/pmc/articles/ PMC3458415/pdf/simycol_73_1_001.pdf. Acceso en: 20 junio 2018.

7. Damm, U.; Cannon, P.F.; Woudenberg, J.H.C.; Crous, P.W. The Colletotrichum acutatum species complex. Studies in Mycology, Utrecht, v.73, p.37-113, 2012. Disponible en: <https://www.ncbi.nlm.nih.gov/ pmc/articles/PMC3458416/pdf/simycol_73_1_002.pdf >. Acceso en: 20 junio 2018

8. Ficke, A.; Gadoury, D. M.; Seem, R. C. Ontogenic resistance and plant disease management: A case study of grape powdery mildew. Phytopathology, Geneva NY, v.92, n.6, p.671-675, 2002. Disponible en: $<$ ht-
tps://apsjournals.apsnet.org/doi/pdf/10.1094/PHYTO.2002.92.6.671>. Acceso en: 12 feb. 2018.

9. Ficke, A.; Gadoury, D.M.; Seem, R.C.; Godfrey, D.; Dry, I.B. Host barriers and responses to Uncinula necator in developing grape berries. Phytopathology, Geneva NY, v.94, n.5, p.438-445, 2004. Disponible en: <https://apsjournals.apsnet.org/doi/pdf/10.1094/PHYTO.2004.94.5.438>. Acceso en: 12 feb. 2018.

10. Guevara, Y.A.; Tapiero, A.L. Diversidad intra-específica de las poblaciones de Colletotrichum spp. afectando caucho en Colombia. In: Congresso Brasileiro de Heveicultura, 5., 2017, Goiânia. Trabalhos científicos 1. Jaboticabal: Fundação de Apoio a Pesquisa, Ensino e Extensão, 2017. p.29-33.

11. Gutiérrez, A. Informe final del proyecto: Modelo territorial validado y ajustado en campo de los cuatro (4) núcleos productores de caucho. Villavicencio: AGROSAVIA, 2017. 54p. Documento Interno,

12. Furtado, E.L.; Silveira, A.P. Doenças da seringueira em viveiros e jardins clonais e seu controle. In: Medrado, M.J.S.; Bernardes, M.S.; Costa, J.D.; Martins, A.N. (ed.). Formação de mudas e plantio de seringueira. Piracicaba: ESALQ, 1992. p.52-64.

13. Furtado, E.L.; Trindade, D.R. Doenças da Seringueira. In: Kimati, H.; Amorim, L.; Rezende, J.A.M.; Bergamim, F.A.; Camargo, L.E.A. (ed.). Manual de Fitopatologia: doenças das plantas cultivadas. 4.ed. São Paulo: Agronômica Ceres, 2005. v.2, p.559-567.

14. Gasparotto, L.; Santos, A.F.; Pereira, J.C.R.; Ferreira, F.A. Doenças da seringueira no Brasil. Brasília, DF: Embrapa, 1997. 168p.

15. Gasparotto, L.; Pereira J.C.R. Doenças da Seringueira no Brasil. 2.ed. Brasília, DF: Embrapa, 2012. 256p.

16. Gonçalves, M.B.; Zieri, R. Leaf anatomy of rubber-tree clones. Scientia Agricola, São Vicente SP, v.60, n.4, p.709-713, 2003. Disponible en: <http://www.scielo.br/pdf/sa/v60n4/a15v60n4.pdf >. Acceso en: 20 nov 2017.

17. Guyot, J.; Omanda, E.; Ndoutoume, A.; Otsaghe, A.; Enjalric, F.; As- 
soumou, H. Effect of controlling Colletotrichum leaf fall of rubber tree on epidemic development and rubber production. Crop Protection, Ámsterdam, v.20, p.581-590, 2001.

18. Hallé, F.; Oldeman, R.A.; Tomlinson, P.B. Tropical Trees and Forest: an architectural analysis. Berlin: Springer, 1978. 441p.

19. Johansen, D.A. Plant micro technique. 1.ed. New York: McGraw-Hill, 1940. 524p.

20. Lieberei, R.; Fock, H.P.; Biehl, B. Cyanogenesis inhibits active pathogen defense in plants: Inhibition by gaseous $\mathrm{HCN}$ of photosynthetic $\mathrm{CO}_{2}$-fixation and respiration in intact leaves. Angewandte Botanik, Hamburg, v.70, p.230-238, 1996.

21. Lieberei, R. South American leaf blight of the rubber tree (Hevea spp.): new steps in plant domestication using physiological features and molecular markers. Annals of Botany, Oxford, v.100, p.1125-1142, 2007. Disponible en: <https://www.ncbi.nlm.nih.gov/pmc/articles/ PMC2759241/pdf/mcm133.pdf>. Acceso en: 20 nov. 2017.

22. Prophet, E.B.; Bills, B.; Arrington, J.B.; Sobin, L.H (ed.). Laboratory Methods in Histotechnology. Washington: American Registry of Pathology, 1992. 279p.
23. Rodríguez T.S.M. Análisis de la Variabilidad Genética de Aislamientos de Microcyclus ulei provenientes de tres zonas caucheras de los Llanos Orientales, mediante la técnica AFLPs. 2012. 126p. Tesis (Maestría en Ciencias Agrarias énfasis en Fitopatología) - Facultad de Ciencias Agrarias, Universidad Nacional de Colombia, Bogotá.

24. Sambugaro, R.; Furtado, E.L.; Rodella, R.A.; Mattos, C.R.R. Anatomia foliar de seringueira (Hevea spp.) e desenvolvimento da infecção por Microcyclus ulei. Summa Phytopathologica, Botucatu, v.30, p 51-56, 2004.

25. Secretaría Técnica de la Cadena del Caucho Natural y su Industria. Comportamiento del caucho natural en Colombia y en el mundo (2002 - 2008). Bogotá: STNCC, 2008. Disponible en: <http://bibliotecadigital.agronet.gov.co/bitstream/11348/5378/1/20084915429_Bullets_Caucho_2008.pdf>. Acceso en: 15 oct. 2017.

26. Sterling, A.; Galindo, L.C.; Parra, J.P. Histopatología de foliolos de plántulas de caucho (Hevea brasiliensis) afectados por hongos fitoparásitos. Momentos de Ciencia, Florencia, v.2, n.2, p.82-88, 2005. 